\title{
THE GENETIC DEFECT CAUSING HUNTINGTON'S DISEASE: REPEATED IN OTHER CONTEXTS?
}

\author{
James F. Gusella, ${ }^{\dagger}{ }^{\dagger}$ Francesca Persichetti, ${ }^{\dagger}$ \\ and Marcy E. MacDonald ${ }^{\dagger}$ \\ *Molecular Neurogenetics Unit, Massachusetts General Hospital East, \\ Charlestown, Massachusetts, U.S.A. ${ }^{\dagger}$ Department of Genetics, Harvard \\ Medical School, Boston, Massachusetts, U.S.A.
}

Huntington's disease (HD) is a dominantly inherited, untreatable neurodegenerative disorder involving progressive chorea, psychiatric changes, and intellectual decline (1). The most characteristic feature of HD is its peculiar movement disorder which begins subtly and progresses to exaggerated dance-like motions that consume the entire body. HD occurs equally in both sexes and is found in all races, but most frequently $(\sim 1$ in $10,000)$ in people of Western European descent (2). Although symptoms may begin at any age, they are usually first manifested between the ages of 30 and 55 and they progressively worsen until death $12-18$ years later.

The clinical progression of HD is paralleled by neuronal degeneration in the brain. The hallmark of HD is the loss of medium spiny GABAergic projection neurons in a gradient progressing along posteroanterior, dorsoventral, and mediolateral axes of the caudate nucleus (3). Prior to cell death, signs of neuronal dysfunction are evident in recurved dendritic endings and changes in spine density, shape, and size (4). The disorder eventually destroys the architecture of the caudate nucleus and the adjacent putamen, although extensive cell loss also occurs in other regions of the basal ganglia and in the deep layers of the cerebral cortex $(5,6)$. Overall brain weight may be reduced by $25 \%$ or more.

Although the proximate cause of the neuronal dysfunction and death is not yet known, it is ultimately due to the presence of a mutant gene

Address correspondence and reprint requests to: James F. Gusella, Molecular Neurogenetics Unit, Massachusetts General Hospital East, Building 149, 13th Street, Charlestown, MA 02129, U.S.A. Tel: 617-726-5724; Fax: 617-726-5735 located near the telomere of the chromosome 4 short arm (7-9). The HD mutation, discovered in 1993, occurs in the first exon of a 67-exon gene encoding a large novel protein (10-12). All HD patients have an expansion in a sequence of consecutive CAG codons that lengthens the stretch from the 10 to 34 repeat units seen on normal chromosomes to more than 36 repeat units. The major outstanding question since discovery of the HD gene is, how does the expanded CAG repeat cause specific neuronal loss? Delineation of similar CAG expansion mutations in a number of other neurodegenerative disorders suggests that the eventual answer may reveal a common mechanism of neuronal toxicity mediated by the mutant gene products.

\section{GENOTYPE:PHENOTYPE CORRELATIONS}

Once a disease gene has been identified, the pursuit of genotype:phenotype correlations can represent a fruitful approach for gaining insight into pathogenesis. In most disorders, this approach involves comparison of the phenotypic effects of different mutations in the same gene. However, numerous studies have established that the HD CAG repeat expansion is the sole mutation responsible for all bona fide inherited and sporadic cases of HD (13-42). Thus, in HD, the "genotype" is an assessment of the number of CAG repeat units in the person's HD allele, whereas the "phenotype" can represent any of a number of descriptive clinical parameters, such as neuro- 
logic symptoms, psychiatric symptoms, cognitive symptoms, age at onset, age at death, rate of disease progression, degree of neuropathology, etc.

To date, the relationship between the size of the CAG repeat and the age at onset of neurologic symptoms has been examined in numerous data sets (43). Most HD cases show adult onset and are associated with CAG allele lengths of 40 to 50 units. Disease alleles with CAG expansion in the 35 to 40 unit range may show very late onset or, in some cases, may be nonpenetrant. By contrast, individuals with more than $60 \mathrm{CAG}$ units typically show onset of HD in their juvenile years. All of these studies report an inverse correlation between CAG repeat length and age at onset of neurologic symptoms. However, there is considerable variation in the age at onset associated with any given CAG repeat length (Fig. 1), suggesting that it can be modified by environmental, genetic, or stochastic modifiers. These effects can be minimized by considering the mean age at neurologic onset associated with any repeat length. By combining a number of published data sets (Fig. 1), we have established that mean age at onset does not vary linearly with CAG repeat length, but rather the relationship is best described $\left(r^{2}=.97\right)$ by an exponential model:

$$
y=284.49 e^{-.043 x}
$$

where $y$ is the age at onset and $x$ is the number of CAG repeat units.

This model is consistent with the view that during the lifetime of the HD individual, there is a progressive decline in the function of the striatum, due to neuronal dysfunction or cell death, that leads to onset of symptoms when a critical threshold of functional loss is reached. The rate of striatal decay in this scenario would be an exponential function of CAG repeat length and one would expect that some degree of neuronal dysfunction or cell loss would precede neurologic manifestations. Extrapolation of neuronal cell counts reported from postmortem HD brains (44) suggests that a threshold at which neurologic onset occurs corresponds to approximately $30 \%$ neuronal loss in the caudate nucleus. Validation of this model will require careful analysis of postmortem HD brains from individuals who expire prior to neurologic onset. The alternative to the gradual neuronal decline model is that the length of the CAG repeat determines, in an exponential manner, the age at which the patho-

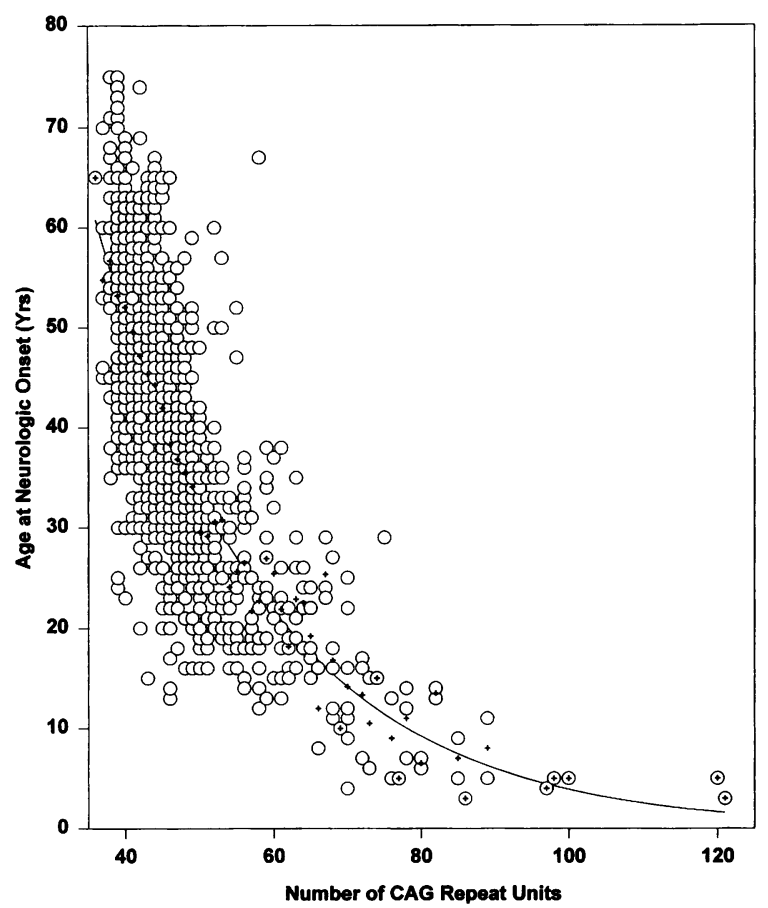

FIG. 1. Relationship between age at neurologic onset and number of HD CAG repeat units

Data compiled from published reports of age at onset (open circles) involving $1226 \mathrm{HD}$ patients $(10,13,21,23-26,28-31,34,36,37,42,75-77)$ permitted the determination of mean age at neurologic onset $(+)$ associated with different numbers of CAG repeats in the disease allele. The solid line represents that predicted by nonlinear regression analysis for the mean age at onset $\left(r^{2}=.97\right)$ using the exponential model presented in the text.

genic process is first triggered with no prior evidence of dysfunction.

Not surprisingly, CAG repeat length has also been inversely correlated with the age of onset of psychiatric manifestations in HD (13). A similar relationship with age at death (Fig. 2) indicates that the presence of an HD-length CAG repeat produces a reduced lifespan (13). However, despite an apparent increased rate of neuronal loss with increasing CAG repeat lengths, the length of time from onset of neurologic symptoms to death does not show a corresponding relationship. Indeed, the duration of disease from neurologic onset to death is remarkably similar $(\sim 15$ years) for different repeat lengths (Fig. 2). Thus, progression to death is not highly correlated with the size of the mutant allele, as is neurologic onset, and it probably involves additional factors beyond degree of neuronal loss. Indeed, direct attempts to relate the patient's overall functional 


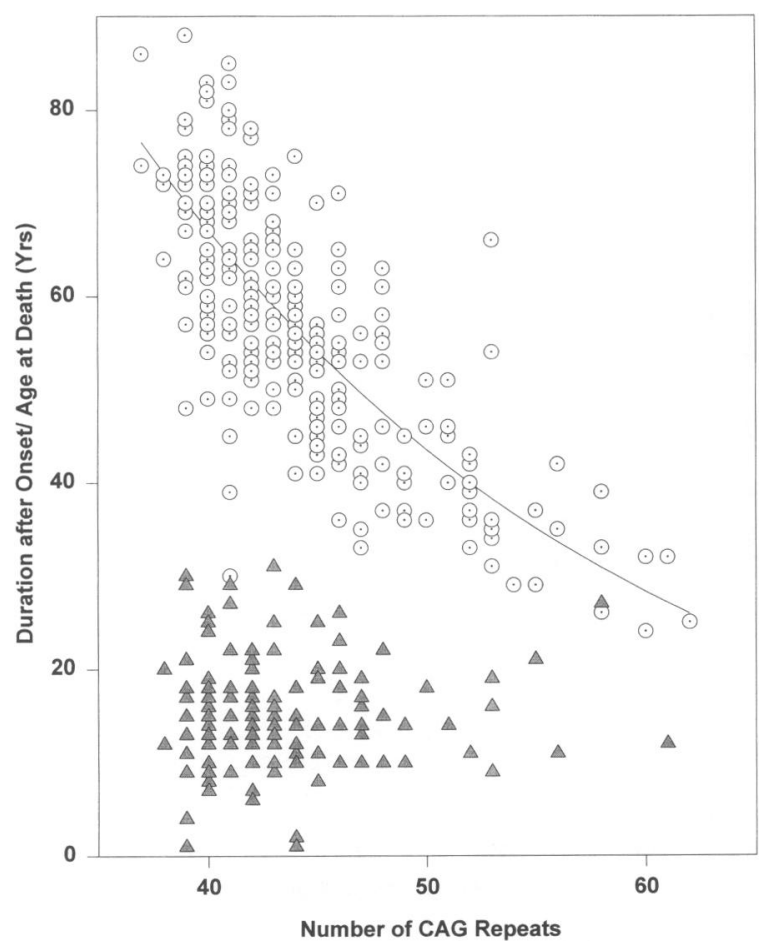

FIG. 2. Duration of disease after onset and age at death versus number of HD CAG repeat units

Age at death (dotted circles) is plotted against the number of CAG repeats for 305 patients whose brains were subjected to postmortem analysis to confirm HD neuropathology (13). The line shows the predicted curve-fit $\left(r^{2}=.49\right)$ based on a similar exponential model to that used Fig. 1. Also shown is the number of years between onset and death (shaded triangles) for 144 patients whose age at onset and death were both known. Linear regression analysis failed to identify any relationship between the disease duration and number of CAG repeat units.

decline with CAG repeat length have yielded conflicting results $(29,30,45)$.

\section{HD GENE PRODUCTS}

The mutant HD gene directs the synthesis of RNA with an expanded CAG segment and consequently a protein with a lengthened stretch of consecutive glutamine residues. Although it is commonly assumed that the dominant mutation acts through the altered protein, both major products differ significantly between normal and disease alleles and therefore the pathogenic effect could equally be due to the altered mRNA. The HD mRNA consists of two alternatively polyadenylated species of $13.5 \mathrm{~kb}$ and $10.5 \mathrm{~kb}$, with the CAG repeat located near the $5^{\prime}$ end, 17 codons downstream from the initiator AUG (10). The mRNA encodes an $\sim 350 \mathrm{kD}$ protein, named huntingtin, with no similarity to other reported sequences except in the low-sequence complexity polyglutamine-polyproline region (encoded by the CAG repeat and an adjacent degenerate CCG repeat) near the $\mathrm{NH}_{2}$-terminus and a motif of unknown function dubbed "HEAT" that has been found in database searches in a variety of unrelated proteins $(10,46)$. Whereas the first 17 amino acids of huntingtin and the remainder of the protein downstream of the polyglutaminepolyproline segment are highly conserved in evolution, the subsequent polyglutaminepolyproline segment is not, and it may be largely dispensable for huntingtin's unknown normal function (47-50). The disease mechanism could operate as a "gain-of-function" that confers a novel, deleterious property on either the $\mathrm{HD}$ mRNA or huntingtin protein without simultaneously interfering with their normal physiological roles.

\section{COMPARISON WITH OTHER CAG TRINUCLEOTIDE REPEAT DISORDERS}

The mutational mechanism in HD, an expanded, meiotically unstable CAG repeat encoding polyglutamine, has been demonstrated in several other genes causing neurodegenerative disorders, which suggests that a common pathogenic mechanism is triggered in each case (51). Kennedy's disease, or spinal bulbar muscular atrophy (SBMA), is caused by an expanded CAG repeat in the $X$-linked androgen receptor gene producing, in males, a progressive loss of anterior horn cells in the spinal cord with consequent progressive muscular weakness $(52,53)$. Dentatorubral-pallidoluysian atrophy (DRPLA) involves neuronal loss in the dentatofugal and pallidofugal systems, and consequent ataxia and choreoathetosis, due to an expanded CAG repeat in a chromosome $12 p$ gene encoding atrophin, another protein of unknown function (54-58). Several spinocerebellar ataxias are caused by an expanded CAG repeat, including spinocerebellar ataxias $1,2,3,6$, and probably 7 .

In SCAl, an expanded CAG repeat on chromosome $6 p$ alters the coding sequence of ataxin-1 (a protein of unknown function) and causes progressive neuronal loss in the cerebellum, the inferior olive, and in various cranial 
nerve nuclei (59). A similar disorder, SCA2, in which the most affected regions are cerebellum, pontine nuclei, inferior olives, and substantia nigra, is caused by an expanded CAG repeat in a novel gene at 12q24.1 (60-62). In SCA3, allelic with Machado-Joseph disease (MJD), an expanded CAG segment in a novel chromosome 14q32.1 gene causes progressive degeneration of the spinocerebellar tracts, with relative sparing of the inferior olive and cerebellar cortex compared with SCA1 and SCA2 (63-70). A CAG repeat in the $\alpha_{1 \mathrm{~A}}$ subunit of a brain voltage-gated calcium channel (CACNL1A4) at 19pl 3 has recently been implicated as the cause of SCA6, another dominant cerebellar ataxia, although the repeat is more stable and the expanded polyglutamine stretch is shorter than in the other CAG neurodegenerative disorders (71). The genetically distinct SCA7, causing spinocerebellar ataxia with retinal degeneration, also shows evidence of expanded CAG in genomic DNA and of lengthened polyglutamine in a $130-\mathrm{kD}$ nuclear protein, but the locus has not yet been cloned $(72,73)$.

As Fig. 3 shows for several of these disorders, a relationship exists between CAG repeat length and age at onset that is comparable to the pattern seen in HD. The age at onset data for SCAl superimpose on the HD curve whereas data for DRPLA and SCA3/MJD are displaced to the right and those for SCA2 are displaced to the left. These findings indicate that in each disorder the degree of CAG expansion necessary to cause a detectable neurologic deficit differs. The slopes of the latter three curves also differ from $\mathrm{HD}$ and SCAl, indicating a greater effect of each additional CAG unit on reducing age at onset. These comparisons suggest that in each disorder, the deleterious effects of the expanded CAG act in a similar manner but on target cell populations and with a CAG length dependence that are dictated by the context in which the mutation is expressed. If the model of gradual neuronal decline to a symptomatic onset threshold is correct, individual differences in the curves would reflect corresponding differences in the threshold for different neuronal cell types and for the contextdependent effect of each embedded CAG repeat on the rate of neuronal decline. In the more severe young-onset cases, the neuronal pathology extends beyond the regions most characteristic of each disorder to parts of the brain that degenerate in one or more of the other CAG repeat disorders. This suggests that each CAG repeat might produce progressive neuronal loss

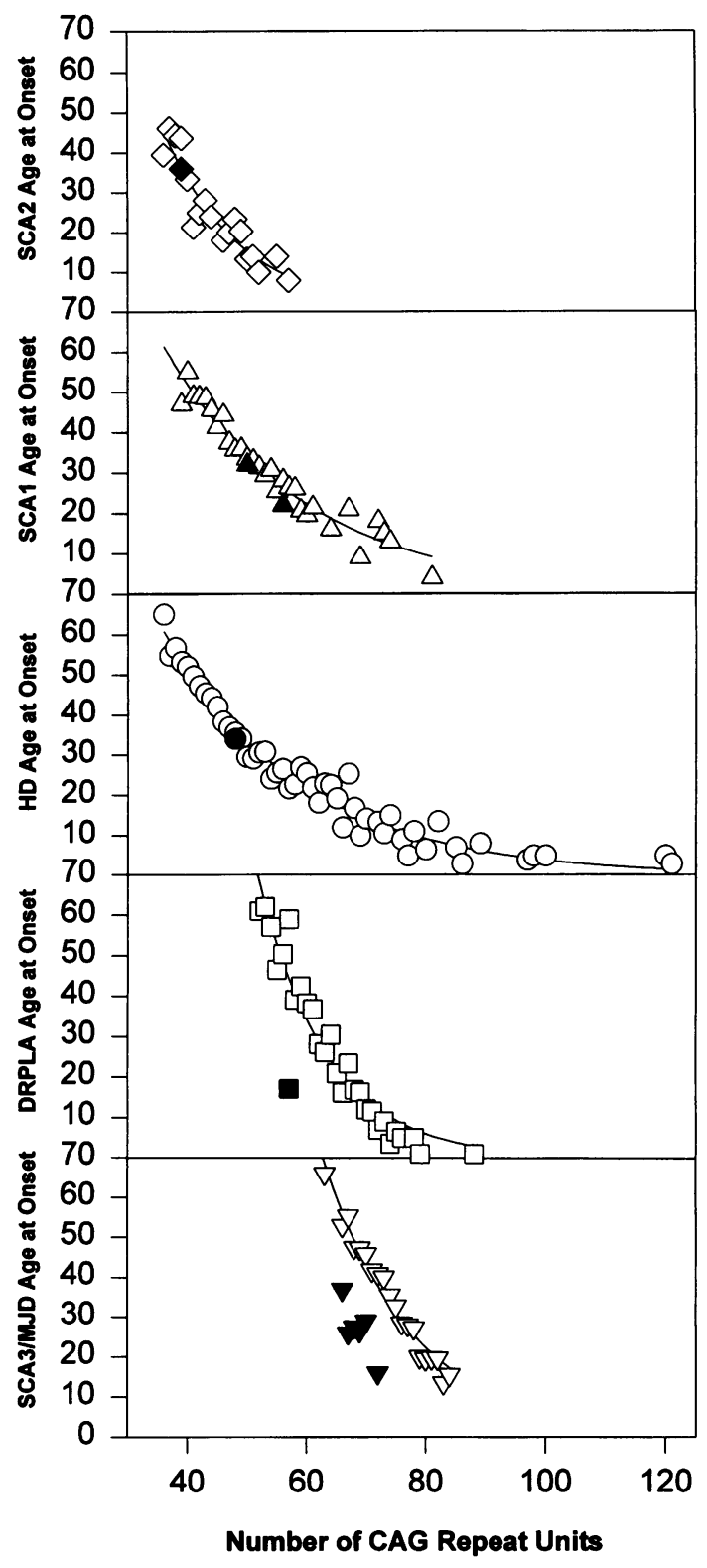

FIG. 3. Onset and repeat length in CAG repeat disorders

Data compiled from published reports were used to calculate mean age at neurologic onset (as in Fig. 1) associated with different CAG repeat lengths in the disease alleles of 92 SCA2 cases (diamonds), 201 SCAl cases (inverted triangles) (78-81), $1226 \mathrm{HD}$ cases (circles) $(10,13,21,23-26,28-31,34,36,37,42$, $75-77), 149$ DRPLA cases (squares) $(58,82-84)$ and $332 \mathrm{MJD} / \mathrm{SCA} 3$ cases (triangles) $(64,68,69,85-87)$. Each panel also shows the curve-fit (line; $r^{2}=.867$ (SCA2); .952 (SCA1); .970 (HD); .943 (DRPLA); .968 (MJD/SCA3) for the mean age at onset with an exponential model similar to that used in Fig. 1. Filled symbols in each panel represent individuals homozygous for the corresponding disease allele, with age at onset plotted against the number of CAG repeats in larger of the two disease alleles (61,81,88-92). 
of more than one neuronal cell population, but with a different rate of decline in each population.

A notable feature of these disorders is the age-at-onset phenotype for individuals homozygous for the disease allele (Fig. 3). In HD, SCAl, and SCA2, a second dose of the disease allele does not aggravate the disease process, as the age at onset observed matches well that expected on the basis of the disease allele with the larger repeat. By contrast, in both DRPLA and SCA3/ MJD individuals, the combined effects of two disease alleles produces an age of onset earlier than that predicted based on either allele alone. The lack of a significant effect of a second disease allele in HD, SCA1, and SCA2, suggests that the presence of a single mutant gene in these disorders produces sufficient product to maximize the rate of neuronal loss that can be caused by a given length of CAG repeat. On the other hand, in DRPLA and MJD/SCA3, the pathogenic triggering mechanism is not saturated in typical heterozygotes as some capacity to accelerate the process with a second disease allele remains.

\section{MECHANISM OF PATHOGENESIS}

Although it is conceivable that the biochemical mechanisms producing neuronal loss in the CAG repeat disorders could differ in each case, the remarkable similarities argue strongly that the pathogenic mechanisms in HD and in the other CAG repeat disorders are closely related. Consequently, defining the pathogenic mechanism in any one of the disorders will probably lead to an understanding of the others and to a delineation of the factors that determine the surprising specificity of neuronal loss. In each case, cell death could either occur as an effect of the long CAG segment in the disease gene mRNA or be due to an expanded polyglutamine segment in the corresponding protein. As each of the genes is unrelated to the others, loss of normal protein function is probably not the primary cause of pathogenesis, although it could certainly contribute to aspects of the disease phenotype (74). Differences in the capacity of the altered gene products in each disorder to trigger the disease process may depend on many factors including their concentration, localization, normal function, and constraints imposed by product structure outside the CAG/polyglutamine region. Hopefully, the ability to compare specific neuronal loss in a number of disorders will accelerate recognition of the steps in pathogenesis that are shared between them, providing the knowledge to develop rational treatments.

\section{ACKNOWLEDGMENTS}

The authors' work has been supported by NIH grants NS16367 and NS32765 and by grants from Bristol-Myers Squibb Inc., the Hereditary Disease Foundation, the Huntington's Disease Society of America, and the Foundation for the Care and Cure of Huntington's Disease (FCCHD). This paper is dedicated to the memory of Mr. Dennis Shea, the FCCHDs founder, in recognition of his many critical contributions to the research effort directed at finding a cure for HD.

\section{REFERENCES}

1. Martin JB, Gusella JF. (1986) Huntington's disease. Pathogenesis and management. N. Engl. J. Med. 315: 1267-1276.

2. Harper PS. (1992) The epidemiology of Huntington's disease. Hum. Genet. 89: 365-376.

3. Vonsattel JP, Myers RH, Stevens TJ, et al. (1985) Neuropathological classification of Huntington's disease. J. Neuropathol. Exp. Neurol. 44: 559-577.

4. Graveland GA, Williams RS, DiFiglia M. (1985) Evidence for degenerative and regenerative changes in neostriatal spiny neurons in Huntington's disease. Science 227: 770773.

5. de la Monte SM, Vonsattel JP, Richardson EP, Jr. (1988) Morphometric demonstration of atrophic changes in the cerebral cortex, white matter, and neostriatum in Huntington's disease. J. Neuropathol. Exp. Neurol. 47: 516-525.

6. Hedreen JC, Peyser CE, Folstein SE, et al. (1991) Neuronal loss in layers V and VI of cerebral cortex in Huntington's disease. Neurosci. Lett. 133: 257-261.

7. Gusella JF, Wexler NS, Conneally PM, et al. (1983) A polymorphic DNA marker genetically linked to Huntington's disease. Nature 306: $234-238$.

8. Gusella JF, Tanzi RE, Anderson MA, et al. (1984) DNA markers for nervous system diseases. Science 225: 1320-1326.

9. Gilliam TC, Tanzi RE, Haines JL, et al. (1987) Localization of the Huntington's disease gene to a small segment of chromosome 4 flanked by D4S10 and the telomere. Cell 50: 565-571. 
10. Huntington's Disease Collaborative Research Group. (1993) A novel gene containing a trinucleotide repeat that is expanded and unstable on Huntington's disease chromosomes. Cell 72: 971-983.

11. Gusella JF, MacDonald ME. (1993) Hunting for Huntington's disease. Mol. Genet. Med. 3: 139-158.

12. Ambrose CM, Duyao MP, Barnes G, et al. (1994) Structure and expression of the Huntington's disease gene: Evidence against simple inactivation due to an expanded CAG repeat. Somat. Cell Mol. Genet. 20: 27-38.

13. Persichetti F, Srinidhi J, Kanaley L, et al. (1995) Huntington's disease CAG trinucleotide repeats in pathologically confirmed post-mortem brains. Neurobiol. Dis. 1: 159166.

14. Bozza A, Malagu S, Calzolari E, et al. (1995) Expansion of a (CAG)n repeat region in a sporadic case of HD. Acta Neurol. Scand. 92: 132-134.

15. Davis MB, Bateman D, Quinn NP, et al. (1994) Mutation analysis in patients with possible but apparently sporadic Huntington's disease. Lancet 344: 714-717.

16. Durr A, Dode C, Hahn V, et al. (1995) Diagnosis of "sporadic" Huntington's disease. J. Neurol. Sci. 129: 51-55.

17. Goldberg YP, Kremer B, Andrew SE, et al. (1993) Molecular analysis of new mutations for Huntington's disease: Intermediate alleles and sex of origin effects. Nat. Genet. 5: 174-179.

18. Myers RH, MacDonald ME, Koroshetz WJ, et al. (1993) De novo expansion of a (CAG)n repeat in sporadic Huntington's disease. Nat. Genet. 5: 168-173.

19. Myers RH, MacDonald ME, Gusella JF. (1993) Discrepancy resolved. Nat. Genet. 5: 215.

20. Kremer B, Goldberg P, Andrew SE, et al. (1994) A worldwide study of the Huntington's disease mutation. The sensitivity and specificity of measuring CAG repeats. N. Engl. J. Med. 330: 1401-1406.

21. Andrew SE, Goldberg YP, Kremer B, et al. (1993) The relationship between trinucleotide (CAG) repeat length and clinical features of Huntington's disease. Nat. Genet. 4: 398-403.

22. Andrew SE, Goldberg YP, Kremer B, et al. (1994) Huntington disease without CAG expansion: Phenocopies or errors in assignment? Am. J. Hum. Genet. 54: 852-863.
23. Barron LH, Warner JP, Porteous $M$, et al. (1993) A study of the Huntington's disease associated trinucleotide repeat in the Scottish population. J. Med. Genet. 30: 1003-1007.

24. Claes S, Van Zand K, Legius E, et al. (1995) Correlations between triplet repeat expansion and clinical features in Huntington's disease. Arch. Neurol. 52: 749-753.

25. Craufurd D, Dodge A. (1993) Mutation size and age at onset in Huntington's disease. J. Med. Genet. 30: 1008-1011.

26. De Rooij KE, De Koning Gans PA, Skraastad MI, et al. (1993) Dynamic mutation in Dutch Huntington's disease patients: Increased paternal repeat instability extending to within the normal size range. J. Med. Genet. 30: 9961002.

27. Dode C, Durr A, Pecheux C, et al. (1993) Huntington's disease in French families: CAG repeat expansion and linkage disequilibrium analysis. C. R. Acad. Sci. III. 316: 1374-1380.

28. Duyao M, Ambrose C, Myers R, et al. (1993) Trinucleotide repeat length instability and age of onset in Huntington's disease. Nat. Genet. 4: 387-392.

29. Illarioshkin SN, Igarashi S, Onodera O, et al. (1994) Trinucleotide repeat length and rate of progression of Huntington's disease. Ann. Neurol. 36: 630-635.

30. Kieburtz K, MacDonald M, Shih C, et al. (1994) Trinucleotide repeat length and progression of illness in Huntington's disease. J. Med. Genet. 31: 872-874.

31. Lucotte G, Aouizerate A, Loreille $\mathrm{O}$, et al. (1994) Trinucleotide repeat elongation in the huntingtin gene in Huntington's disease patients from 85 French families. Genet Couns. 5: 321-328.

32. Masuda N, Goto J, Murayama N, et al. (1995) Analysis of triplet repeats in the huntingtin gene in Japanese families affected with Huntington's disease. J. Med. Genet. 32: 701-705.

33. Meszaros $\mathrm{K}$, Willinger $\mathrm{U}$, Heiden $\mathrm{AM}$, et al. (1994) Huntington chorea: (CAG)n repeats on gene IT 15 in Austria (in German). Wien Klin. Wochenschr. 106: 671-672.

34. Norremolle A, Riess O, Epplen JT, et al. (1993) Trinucleotide repeat elongation in the huntingtin gene in Huntington disease patients from 71 Danish families. Hum. Mol. Genet. 2: 1475-1476.

35. Norremolle A, Sorensen SA, Fenger K, et al. (1995) Correlation between magnitude of 
CAG repeat length alterations and length of the paternal repeat in paternally inherited Huntington's disease. Clin. Genet. 47: 113117.

36. Novelletto A, Persichetti F, Sabbadini G, et al. (1994) Analysis of the trinucleotide repeat expansion in Italian families affected with Huntington disease. Hum. Mol. Genet. 3: 93-98.

37. Snell RG, MacMillan JC, Cheadle JP, et al. (1993) Relationship between trinucleotide repeat expansion and phenotypic variation in Huntington's disease [see comments]. Nat. Genet. 4: 393-397.

38. Soong BW, Wang JT. (1995) A study on Huntington's disease associated trinucleotide repeat within the Chinese population. Proc. Natl. Sci. Counc. Repub. China B 19: 137-142.

39. Trottier Y, Biancalana V, Mandel JL. (1994) Instability of CAG repeats in Huntington's disease: Relation to parental transmission and age of onset. J. Med. Genet. 31: 377-382.

40. Whitefield JE, Williams L, Snow K, et al. (1996) Molecular analysis of the Huntington's disease gene in New Zealand. N. Z. Med. J. 109: 27-30.

41. Xuereb JH, MacMillan JC, Snell R, et al. (1996) Neuropathological diagnosis and CAG repeat expansion in Huntington's disease. J. Neurol. Neurosurg. Psychiatry 60: 7881.

42. Zuhlke C, Riess O, Schroder K, et al. (1993) Expansion of the (CAG)n repeat causing Huntington's disease in 352 patients of German origin. Hum. Mol. Genet. 2: 1467-1469.

43. Gusella JF, MacDonald ME. (1995) Huntington's disease. Semin. Cell Biol. 6: 21-28.

44. Furtado S, Suchowersky O, Rewcastle B, et al. (1996) Relationship between trinucleotide repeats and neuropathological changes in Huntington's disease. Ann. Neurol. 39: 132-136.

45. Brandt J, Bylsma FW, Gross R, et al. (1996) Trinucleotide repeat length and clinical progression in Huntington's disease. Neurology 46: 527-531.

46. Andrade MA, Bork P. (1995) HEAT repeats in the Huntington's disease protein [letter]. Nat. Genet. 11: 115-116.

47. Baxendale S, Abdulla S, Elgar G, et al. (1995) Comparative sequence analysis of the human and pufferfish Huntington's disease genes. Nat. Genet. 10: 67-76.

48. Barnes GT, Duyao MP, Ambrose CM, et al. (1994) Mouse Huntington's disease gene ho- molog (Hdh). Somat. Cell Mol. Genet. 20: 8797.

49. Lin B, Nasir J, MacDonald H, et al. (1994) Sequence of the murine Huntington disease gene: Evidence for conservation, alternate splicing and polymorphism in a triplet (CCG) repeat. Hum. Mol. Genet. 3: 85-92 [Erratum in Hum. Mol. Genet. (1994) 3: 530].

50. Schmitt I, Bachner D, Megow D, et al. (1995) Expression of the Huntington disease gene in rodents: Cloning the rat homologue and evidence for down-regulation in nonneuronal tissues during development. Hum. Mol. Genet. 4: 1173-1182.

51. Gusella JF, MacDonald ME. (1996) Trinucleotide instability: A repeating theme in human inherited disorders. Annu. Rev. Med. 47: 201-209.

52. Fischbeck KH. (1995) The expanded trinucleotide repeat in Kennedy's disease. Proc. Assoc. Am. Physicians 107: 228-230.

53. Brooks BP, Fischbeck KH. (1995) Spinal and bulbar muscular atrophy: A trinucleotiderepeat expansion neurodegenerative disease. Trends Neurosci. 18: 459-461.

54. Burke JR, Wingfield MS, Lewis KE, et al. (1994) The Haw River syndrome: Dentatorubropallidoluysian atrophy (DRPLA) in an African-American family. Nat. Genet. 7: 521-524.

55. Ikeuchi T, Koide R, Onodera O, et al. (1995) Dentatorubral-pallidoluysian atrophy (DRPLA). Molecular basis for wide clinical features of DRPLA. Clin. Neurosci. 3: 23-27.

56. Ikeuchi $\mathrm{T}$, Onodera $\mathrm{O}$, Oyake $M$, et al. (1995) Dentatorubral-pallidoluysian atrophy (DRPLA): Close correlation of CAG repeat expansions with the wide spectrum of clinical presentations and prominent anticipation. Semin. Cell Biol. 6: 37-44.

57. Koide R, Ikeuchi T, Onodera O, et al. (1994) Unstable expansion of CAG repeat in hereditary dentatorubral-pallidoluysian atrophy (DRPLA). Nat. Genet. 6: 9-13.

58. Nagafuchi S, Yanagisawa $H$, Sato $K$, et al. (1994) Dentatorubral and pallidoluysian atrophy expansion of an unstable CAG trinucleotide on chromosome 12p. Nat. Genet. 6: 14-18.

59. Zoghbi HY, Orr HT. (1995) Spinocerebellar ataxia type 1. Semin. Cell Biol. 6: 29-35.

60. Pulst SM, Nechiporuk A, Nechiporuk T, et al. (1996) Moderate expansion of a normally biallelic trinucleotide repeat in spinocerebellar ataxia type 2. Nat. Genet. 14: 269-276. 
61. Sanpei K, Takano H, Igarashi S, et al. (1996) Identification of the spinocerebellar ataxia type 2 gene using a direct identification of repeat expansion and cloning technique, DIRECT. Nat. Genet. 14: 277-284.

62. Imbert G, Saudou F, Yvert G, et al. (1996) Cloning of the gene for spinocerebellar ataxia 2 reveals a locus with high sensitivity to expanded CAG/glutamine repeats. Nat. Genet. 14: 285-291.

63. Durr A, Stevanin G, Cancel G, et al. (1996) Spinocerebellar ataxia 3 and Machado-Joseph disease: Clinical, molecular, and neuropathological features. Ann. Neurol. 39: 490499.

64. Cancel G, Abbas N, Stevanin G, et al. (1995) Marked phenotypic heterogeneity associated with expansion of a CAG repeat sequence at the spinocerebellar ataxia 3/Machado-Joseph disease locus. Am. J. Hum. Genet. 57: 809-816.

65. Haberhausen G, Damian MS, Leweke F, et al. (1995) Spinocerebellar ataxia, type 3 (SCA3) is genetically identical to MachadoJoseph disease (MJD). J. Neurol. Sci. 132: 71-75.

66. Kawaguchi Y, Okamoto T, Taniwaki M, et al. (1994) CAG expansions in a novel gene for Machado-Joseph disease at chromosome 14q32.1. Nat. Genet. 8: 221-228.

67. Higgins JJ, Nee LE, Vasconcelos $\mathrm{O}$, et al. (1996) Mutations in American families with spinocerebellar ataxia (SCA) type 3: SCA3 is allelic to Machado-Joseph disease. Neurology 46: 208-213.

68. Matilla T, McCall A, Subramony SH, et al. (1995) Molecular and clinical correlations in spinocerebellar ataxia type 3 and MachadoJoseph disease. Ann. Neurol. 38: 68-72.

69. Schols L, Vieira-Saecker AM, Schols S, et al. (1995) Trinucleotide expansion within the MJDl gene presents clinically as spinocerebellar ataxia and occurs most frequently in German SCA patients. Hum. Mol. Genet. 4: 1001-1005.

70. Schols L, Amoiridis G, Langkafel $M$, et al. (1995) Machado-Joseph disease mutations as the genetic basis of most spinocerebellar ataxias in Germany. J. Neurol. Neurosurg. Psychiatry 59: 449-450.

71. Zhuchenko O, Bailey J, Bonnen P, et al. (1997) Autosomal dominant cerebellar ataxia (SCA6) associated with small polyglutamine expansions in the alphal A-voltage- dependent calcium channel. Nat. Genet. 15: 62-68.

72. Trottier Y, Lutz Y, Stevanin G, et al. (1995) Polyglutamine expansion as a pathological epitope in Huntington's disease and four dominant cerebellar ataxias. Nature 378: 403-406.

73. Lindblad K, Savontaus ML, Stevanin G, et al. (1996) An expanded CAG repeat sequence in spinocerebellar ataxia type 7. Genome Res. 6: 965-971.

74. MacLean HE, Choi WT, Rekaris G, et al. (1995) Abnormal androgen receptor binding affinity in subjects with Kennedy's disease (spinal and bulbar muscular atrophy). J. Clin. Endocrinol. Metab. 80: 508-516.

75. Kremer B, Squitieri F, Telenius $\mathrm{H}$, et al. (1993) Molecular analysis of late onset Huntington's disease. J. Med. Genet. 30: 991-995.

76. Stine OC, Pleasant N, Franz ML, et al. (1993) Correlation between the onset age of Huntington's disease and length of the trinucleotide repeat in IT-15. Hum. Mol. Genet. 2: 1547-1549.

77. Rubinsztein DC, Barton DE, Davison BC, et al. (1993) Analysis of the huntingtin gene reveals a trinucleotide-length polymorphism in the region of the gene that contains two CCG-rich stretches and a correlation between decreased age of onset of Huntington's disease and CAG repeat number. Hum. Mol. Genet. 2: 1713-1715.

78. Ranum LP, Chung MY, Banfi S, et al. (1994) Molecular and clinical correlations in spinocerebellar ataxia type I: Evidence for familial effects on the age at onset. Am. J. Hum. Genet. 55: 244-252.

79. Matilla T, Volpini V, Genis D, et al. (1993) Presymptomatic analysis of spinocerebellar ataxia type 1 (SCAl) via the expansion of the SCAl CAG-repeat in a large pedigree displaying anticipation and parental male bias. Hum. Mol. Genet. 2: 2123-2128.

80. Dubourg O, Durr A, Cancel G, et al. (1995) Analysis of the SCAl CAG repeat in a large number of families with dominant ataxia: Clinical and molecular correlations. Ann. Neurol. 37: 176-180.

81. Goldfarb LG, Vasconcelos O, Platonov FA, et al. (1996) Unstable triplet repeat and phenotypic variability of spinocerebellar ataxia type 1. Ann. Neurol. 39: 500-506.

82. Warner TT, Williams LD, Walker RW, et al. (1995) A clinical and molecular genetic study of dentatorubropallidoluysian atrophy 
in four European families. Ann. Neurol. 37: 452-459.

83. Komure O, Sano A, Nishino N, et al. (1995) DNA analysis in hereditary dentatorubralpallidoluysian atrophy: Correlation between CAG repeat length and phenotypic variation and the molecular basis of anticipation. $\mathrm{Neu}$ rology 45: 143-149.

84. Norremolle A, Nielsen JE, Sorensen SA, et al. (1995) Elongated CAG repeats of the B37 gene in a Danish family with dentato- rubropallido-luysian atrophy. Hum. Genet. 95: 313-318.

85. Ranum LP, Lundgren JK, Schut LJ, et al. (1995) Spinocerebellar ataxia type 1 and Machado-Joseph disease: Incidence of CAG expansions among adult-onset ataxia patients from 311 families with dominant, recessive, or sporadic ataxia. Am. J. Hum. Genet. 57: 603-608.

86. Maruyama $H$, Nakamura $S$, Matsuyama $Z$, et al. (1995) Molecular features of the CAG repeats and clinical manifestation of Machado-Joseph disease. Hum. Mol. Genet. 4: 807-812.

87. Maciel P, Gaspar C, DeStefano AL, et al.
(1995) Correlation between CAG repeat length and clinical features in Machado-Joseph disease. Am. J. Hum. Genet. 57: 54-61.

88. Lang AE, Rogaeva EA, Tsuda T, et al. (1994) Homozygous inheritance of the MachadoJoseph disease gene. Ann. Neurol. 36: 443447.

89. Sato K, Kashihara K, Okada S, et al. (1995) Does homozygosity advance the onset of dentatorubral-pallidoluysian atrophy? Neurology 45: 1934-1936.

90. Takiyama Y, Igarashi S, Rogaeva EA, et al. (1995) Evidence for inter-generational instability in the CAG repeat in the MJD l gene and for conserved haplotypes at flanking markers amongst Japanese and Caucasian subjects with Machado-Joseph disease. Hum. Mol. Genet. 4: 1137-1146.

91. Myers RH, Leavitt J, Farrer LA, et al. (1989) Homozygote for Huntington disease. Am. J. Hum. Genet. 45: 615-618.

92. Lerer I, Merims D, Abeliovich D, et al. (1996) Machado-Joseph disease: Correlation between the clinical features, the CAG repeat length and homozygosity for the mutation. Eur. J. Hum. Genet. 4: 3-7. 